\title{
CINEMA-EDUCAÇÃO NA AMÉRICA LATINA: REFLEXÕES METODOLÓGICAS A PARTIR DO DIÁLOGO BRASIL - CUBA
}

\begin{abstract}
CINEMA-EDUCATION IN LATIN AMERICA: METHODOLOGICAL REFLECTIONS FROM THE BRAZIL - CUBA DIALOGUE

CINE-EDUCACIÓN EN AMÉRICA LATINA:

REFLEXIONES METODOLÓGICAS A PARTIR DEL DIÁLOGO

BRASIL - CUBA

Fernanda Omelczuk Walter ${ }^{1}$

RESUMO

O texto acompanha as transformações no pensamento, nas práticas e nas políticas em cinema-educação para a infância e a juventude na América Latina a partir das diferentes motivações pedagógicas e inspirações metodológicas que impulsionaram o campo. Para tanto, examinamos pesquisas que mapeiam práticas em educação audiovisual no Brasil, refletimos sobre a criação e os encontros da Rede UNIAL em Cuba e da Rede KINO no Brasil e apresentamos referências de uma pesquisa que percorreu projetos audiovisuais em Havana. Nesta trajetória, identificamos um elo metodológico comum, que outrora propiciou o surgimento e a difusão de iniciativas em cinema-educação no continente e novas apropriações na relação do cinema com a educação, as quais emergem de demandas e desafios contemporâneos.
\end{abstract}

PALAVRAS-CHAVE: Cinema e educação. Aprendizagem de cinema. Cinema e audiovisual. Cinema latinoamericano.

\begin{abstract}
The text accompanies the transformations in thought, practices and policies in cinema-education for childhood and youth in Latin America from the different pedagogical motivations and methodological inspirations that have driven the field. In order to do so, we examine researches that map practices in audiovisual education in Brazil, reflect on the creation and meetings of the UNIAL Network in Cuba and the KINO Network in Brazil and present references of a research that covered audiovisual projects in Havana. In this trajectory we identified a common methodological link that once led to the emergence and diffusion of initiatives in cinema-education in the continent and new appropriations in the relationship between cinema and education that emerge from contemporary demands and challenges.
\end{abstract}

KEYWORDS: Cinema and education. Cinema learning. Cinema and audiovisual. Latin America cinema.

\section{RESUMEN}

El texto acompaña las transformaciones en el pensamiento, en las prácticas y en las políticas en cine-educación para la infancia y la juventud en América Latina desde las diferentes motivaciones pedagógicas e inspiraciones metodológicas que impulsaron el campo. Para ello, examinamos investigaciones que mapean prácticas en educación audiovisual en Brasil, reflexionamos sobre la creación y los encuentros de la Red UNIAL en Cuba y de la Red KINO en Brasil y presentamos referencias de una investigación que recorrió proyectos audiovisuales en La Habana. En esa trayectoria identificamos un vinculo metodológico común que otrora propició el

\footnotetext{
1 Doutorado em Educação - Universidade Federal do Rio de Janeiro (UFRJ) - Rio de Janeiro, RJ - Brasil. Professora Adjunta - Universidade Federal de São João Del-Rei (UFSJ) - São João del-Rei, MG - Brasil. E-mail: fernandaow@gmail.com
}

Submetido em: 11/12/2017 - Aceito em: 24/06/2018

(C) ETD-Educação Temática Digital Campinas, SP $\quad$ v.21 $\quad$ n.1 $\quad$ p.105-125 jan./mar. 2019 
surgimiento y la difusión de iniciativas en cine-educación en el continente y nuevas apropiaciones en la relación del cine con la educación que emergen de demandas y desafíos contemporáneos.

PALABRAS-CLAVE: Cine y educación. Aprendizaje de cine. Cine y audiovisual. Cine latino americano.

\section{APRESENTAÇÃO}

As reflexões que compartilho neste artigo foram elaboradas a partir da pesquisa que realizei em Cuba como etapa do "doutorado sanduíche"2 no contexto da tese "O que se aprende quando se aprende cinema no hospital?" defendida em 2016 no Programa de Pósgraduação (PPGE) em Educação da UFRJ. Foi durante a pesquisa no Brasil, na investigação de filmes a serem exibidos para crianças e no levantamento bibliográfico sobre cinemaeducação, que me deparei com uma convergência de preocupações e ações sobre essas questões que aproximavam o Brasil de outros países da América Latina. Nesse contexto, submeti um plano de pesquisa para ser desenvolvido em Havana - berço dos primeiros encontros de educadores e pesquisadores do campo.

Nas linhas a seguir, procurei refletir sobre algumas das discussões que iniciei na tese: o campo teórico-metodológico da educação audiovisual na América Latina e as visitas aos projetos audiovisuais em Havana, onde entrevistei educadores sobre suas metodologias e práticas articulando, para fins deste artigo, com proposições de pensadores, educadores e cineastas latino-americanos (especificamente José Martí, Simón Rodríguez e García Espinosa). Estes, mesmo tendo escrito em tempos de outrora, sugerem, cada um ao seu modo, reflexões sobre as imagens e o cinema, as quais nos convidam a pensar as ações e metodologias em cinema-educação hoje. Essa, ao menos, é uma das apostas do texto que inicio.

\section{INTRODUÇÃO}

Trincheiras de ideias valem mais do que trincheiras de pedras (MARTí, 1891).

Não foram poucos os sonhos e projetos que tentaram libertar e aproximar os países centrais e do sul. E nunca deixaram de ser atuais. Tampouco, foram fracas as resistências a esse desejo. Avanços, oposições, insurgências e retrocessos marcaram os séculos XIX e XX na América colonizada.

Ao conhecer, de modo iniciático, alguns nomes e ideias que marcaram e inspiraram esses primeiros sonhos de libertação e integração territorial de nossa América, damo-nos conta de que as batalhas pela independência significaram a luta por um modo próprio de se organizar, de se educar e de conviver. Lutou-se pela afirmação e história da cultura dos povos autóctones que aqui residiam e pela invenção como único caminho possível de

\footnotetext{
${ }^{2}$ Esta parte da pesquisa contou com apoio da Bolsa Capes PDSE (Programa de Doutorado Sanduíche no Exterior).
} 
resistência à imitação imperialista, a qual impunha desejos, gostos, estéticas e sonhos. Tratava-se, portanto, de uma guerra pela libertação do imaginário - o "imaginário da brancura", disse Castro-Gómez (2005), que dita crenças religiosas, vestimentas, comportamentos e formas de produzir e transmitir conhecimento. E passados mais de duzentos anos do nascimento de Simón Rodriguez ou mais de cem da morte de José Martí, ainda se trata.

Estamos nos sonhos de Simón Rodriguez (1769-1854) e José Martí (1853-1895) mesmo que pouco saibamos sobre eles. Nosso desconhecimento acerca de quem foram algumas dessas personalidades são as primeiras marcas de uma trincheira ideológica imposta aos povos das Américas Central e do Sul. Para tentar perfurar essa barricada, dialogo neste trabalho com algumas ideias introdutórias partindo dos textos "Nuestra America" (1891), de Martí, e "Sociedades Americanas" (1842), de Rodríguez, presentes na ontologia deste: "Inventamos ou erramos" (2016).

Foram crianças cubanas que me apresentaram a José Martí, em Havana, na ocasião em que conversávamos sobre o nascimento do cinema em uma oficina de audiovisual. Ao contar que a sétima arte havia nascido em 1895, elas disseram que esse era o mesmo ano da morte de José Martí. Curiosa coincidência histórica, a qual nos levou embora um poetasoldado-revolucionário, que lutou pela preservação e defesa de um imaginário latinoamericano próprio, e nos trouxe, no mesmo ano, uma arte que inventa e compartilha sonhos com uma impressão de realidade nunca vista antes. O que Martí teria dito sobre o cinema e essa potência?

José Martí escreveu muito: manifestos, ensaios, poesias e literatura para crianças e adultos. Diz-se que a escrita foi a sua arma. $\mathrm{O}$ amadurecimento gradativo de suas ideias fortaleceu a consciência latino-americana numa unidade continental para impedir mais um movimento de imposição e exploração que observava vir do Norte. Assim, a história da Revolução Cubana reconhece esse pensador como mentor ideológico do movimento " 26 de julho", que engendrou a revolução em 1959, libertando, dessa vez, a ilha do domínio estadunidense.

Antecipando o contrapelo benjaminiano da história, Martí se recusou a escrever a história da América a partir dos olhos estrangeiros, pois entendia que nossa história original e natural foi interrompida num primeiro momento com a chegada do colonizador e posteriormente com a importação do pragmatismo e materialismo do Norte. A colonização foi a negação do ser latino-americano, de nossa identidade e biografia próprias - que não é a que nos contam nos livros eurocêntricos. Temos uma originalidade histórica que precisa ser escrita: "A história da América, dos incas para cá, deve ser ensinada minuciosamente, mesmo que não se ensine a dos arcontes da Grécia. A nossa Grécia é preferível à Grécia que não é nossa. Nos é mais necessária" (MARTí, 1891, p. 2). 
Nossa América mestiça, como assim Martí se referia, possui conflitos específicos e caraterísticas peculiares, uma psicologia social e espiritual irreproduzível. As soluções e análises também devem ser únicas e inventivas. É preciso contemplar os saberes e a participação dos indígenas, dos negros, dos camponeses, dos pobres; enfim, de toda a população. Isso não significa negar os saberes estrangeiros, mas se aproximar deles de um modo pessoal e íntimo, num exercício de tradução daquilo que é pensado e produzido no exterior sem uma leitura subalterna. Desse modo, a célebre frase de Martí (1891, p. 4), "o vinho é de banana. E se sair ácido é o nosso vinho!" expressa a força que o libertador cubano conferia à mestiçagem, característica própria da América Latina, afirmando a cultura particular de um povo na invenção de um jeito próprio de fazer e reinventar produtos, ideias e hábitos que vêm de fora.

Tal como Simón Rodríguez, que o antecedeu quase um século antes, os anos quando viveu no exílio não provocaram em Martí um deslumbramento e discurso de cópia da modernidade alheia, e sim um olhar crítico para a complexidade de nossa América fragmentada por dentro e por fora. Ambos aprenderam na distância a ver que a ameaça não é só externa, mas interna. A supervalorização do progresso produziu uma "vergonha" e negação das culturas tradicionais, de não reconhecimento e solidariedade com os países vizinhos, que monopoliza até hoje o imaginário latino-americano.

Conheci Simón Rodríguez no livro "O mestre inventor. Relatos de um viajante educador", de Walter Kohan (2013), no qual a vida errante deste, que mais ficou conhecido como o mestre do libertador Simon Bolívar, nos é narrada. Rodríguez foi professor, filósofo inventor e viajante, tendo vivido na Jamaica, Estados Unidos e Europa, retornando, então, à Venezuela, sua terra natal, com passagens pela Colômbia, Equador, Peru, Bolívia e Chile. Por onde esteve, aprendeu, ensinou, escreveu e construiu escolas. Numa época em que as instituições educativas eram exclusividade da elite econômica, Rodríguez defendia o acesso igualitário a elas às crianças de todas as classes sociais, propondo à escola a tarefa de restituir ao povo o que é do povo: sua terra, cultura, linguagem, pensamento e vida; uma educação descolonizadora e emancipadora, que fomentou as bases da educação popular.

O estilo com que Rodríguez viaja, olha e se relaciona com o estrangeiro é inspiração para a compreensão e reinvenção de nossa realidade. $O$ encontro com o outro lhe permite ver a si mesmo. Numa ação que antecede o movimento modernista antropofágico, digere o estrangeiro transformando-o em seu. Assim, em suas andanças, aprendeu com o patriotismo francês de Napoleão, por exemplo, a amar sua própria pátria, e não a reproduzir ou aspirar a hábitos franceses: "Deixemos a França e vejamos a América. Veja a Europa como inventa e a América como imita" (RODRíGUEZ, 2016, p. 132-133).

Em comum, Rodríguez e Martí sonharam com uma América unida, livre e de "personalidade" própria, emancipada. Perceberam, desde cedo, o que o cotidiano contemporâneo nos permite sentir cada vez mais forte: a colonização mais cruel é invisível

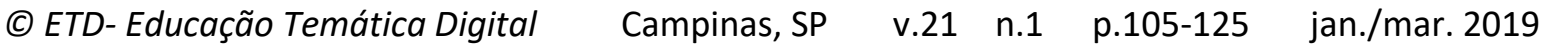


aos olhos da razão - é a do imaginário. Ela dita desejos, sonhos e modos de consumo, despreza a pátria e dirige a admiração e o amor ao opressor.

Trago esses autores para pensar as políticas em cinema-educação em nosso continente sulista, porque, ainda que poucas referências diretas sejam feitas a eles, os ecos de suas proposições podem ser encontrados em gerações de cineastas, educadores, pesquisadores e entusiastas da sétima arte e da história da educação cinematográfica na América Latina. Por isso, podemos refletir sobre as colocações e resistências que esses autores nos trazem pausando o olhar na circulação das imagens e em como elas educam, colonializam, mostram, escondem e criam realidades e uma versão (única) da história.

Antigos e parecidos sonhos de libertação se encontram no fazer e no pensar nosso cinema, especialmente a partir da Revolução Cubana, que reconheceu, na potência de invenção de mundos da sétima arte, território de disputa, narrativas, representações e meio de ação basilar; portanto, para a construção cultural da nação cubana que emergia e da identidade latino-americana que se almejava fortalecer na vizinhança. Teriam Martí e Rodríguez sonhado com isso? Como o cinema e/ou uma educação cinematográfica entraria(m) em suas lutas pela emancipação?

\section{O CINEMA OU A “MÁQUINA DE PRODUZIR SONHOS” NA AMÉRICA LATINA}

Experimentar a sensação onírica e as operações da imaginação que a magia das projeções de luzes e sombras incitavam era o principal atrativo para o primeiro público europeu a frequentar as salas escuras no final do século XIX e início do século XX. Em meio a outras atrações circenses, esse pré-cinema, ou cinema dos primórdios, aproximou razão, fantasia e realidade. Funcionando muitas vezes em guetos, subúrbios e porões de bairros marginalizados, esses primeiros experimentos com a luz, teatros de sombras, projeções de lanternas mágicas e efeitos visuais diversos aproximavam as invenções adultas da fascinação infantil como podemos acompanhar na história da família Skaladanowsky, que nos conta Lucy em "Um truque de luz" (MACHADO, 1997).

Na América Latina, entretanto, esse pré-cinema, ou cinema dos primórdios, não causou imediatamente o mesmo impacto social e frenesi artístico. Segundo Torchia (2012), aqui, ele funcionou como mais um instrumento de domínio das antigas colônias, mais um artefato fabricado e importado, com a finalidade de lucro para aqueles que serviam de intermediários entre os fabricantes e os consumidores nativos. As jovens nações latinoamericanas consumiam as imagens estrangeiras, sendo que, no início, seus processos criativos estavam sob o influxo das obras europeias e norte-americanas. 
Era um período de intensa valorização das invenções técnicas, da ciência e dos meios de comunicação - símbolos da modernidade. O cinema surgia como a evolução mais sofisticada para o registro de imagens, consequência de uma série de inventos anteriores.

Nos anos 1920 e 1930, período em que o Brasil se consolidava como República, a forte impressão de realidade fascinou políticos e educadores, os quais viram no cinema um instrumento capaz de difundir imagens que contribuíssem para a construção de uma consciência histórica, resgatando a origem do povo brasileiro e sua formação, edificando uma espécie de identidade e orgulho nacional, e divulgando o modo de ser do homem do campo, seus hábitos, sua música e seus costumes. Educadores, cineastas e Estado compartilhavam concepções em torno da necessidade de educar o povo (CATELLI, 2007).

Visto com adoração e suspeita, foi preciso, entretanto, definir, já naquela época, qual cinema serviria aos ideais modernos. Tratava-se de escolher, ver e fazer o cinema certo, já que determinados modelos, imagens e cenas eram considerados prejudiciais para a formação dos jovens e crianças. Naquele momento, o mundo todo preocupava-se com os efeitos do cinema; e na América Latina, não foi diferente (SALIBA, 2003).

É nesse sentido que os ecos dos pensadores cubano e venezuelano (Martí e Rodríguez) continuaram influenciando e ainda atravessando nosso continente. A publicação em 1970 do manifesto "Por un cine imperfecto", do cineasta Julio García Espinosa (1970), por exemplo, reúne reflexões sobre um modo próprio de produzir, difundir e narrar que a América Latina deveria inventar, e não imitar. Em sua opinião, o cinema cubano, fruto do processo revolucionário, era imperfeito, pois demarcava lugares para artistas e espectadores, reafirmando a divisão de tarefas e excluindo o povo da criação de suas próprias imagens. Essa era a primeira imperfeição, talvez ainda necessária naquele momento inicial.

Conforme o seu ponto de vista, nos anos pós-revolução, a arte cinematográfica deveria difundir os valores socialistas, reescrever a história da América Latina e resgatar e recriar o imaginário usurpado pelas colonizações europeia e norte-americana. Esse cinema é imperfeito, "porque ainda é realizado por um corpo de especialistas, os cineastas, para um novo destinatário: as massas revolucionárias do Terceiro Mundo" (NUÑEZ, 2012, p. 179).

Mas, além de colocar em circulação imagens que outrora ficaram fora de campo: paisagens, sotaques, músicas, afetos, cores, modos de se comportar, de conviver etc., outra imperfeição que marcaria o cinema latino-americano diz respeito aos recursos tecnológicos de que dispomos para sua produção e condições de exibição. Numa alusão ao "vinho de banana", García Espinosa (1970) parece dizer que não é preciso ter a "qualidade" do cinema industrial norte-americano, pois o que importa é que seja "nosso".

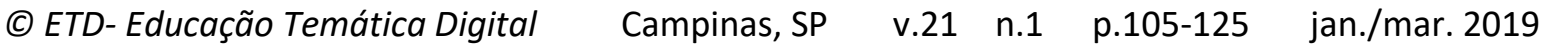


Veremos, mais adiante, que as proposições levantadas pelo cineasta cubano podem ser proveitosas na conjuntura da Lei no 13.006 (BRASIL, 2014), a fim de pensarmos nas condições estruturais - imperfeitas - das escolas públicas brasileiras para exibição dos filmes e na aparelhagem que dispomos para a produção audiovisual, e ainda no que filmamos nesses contextos em termos de temáticas e estéticas. A despeito da fragmentação latino-americana, elos e sonhos comuns parecem ter sobrevivido e adormecidos em nosso imaginário. Uma mestiçagem metodológica atravessa e reinventa práticas variadas nos projetos audiovisuais, que não param de nascer e se multiplicar na América Latina.

\section{CINEMA-EDUCAÇÃO NA AMÉRICA LATINA}

Desenvolvida inicialmente por grupos católicos preocupados com a moral que circulava nos filmes que aqui chegavam, as organizações eclesiásticas ajudaram a organizar os primeiros cineclubes da região além de cursos de cinema e publicações de críticas, prêmios e classificações dos filmes (LISBOA, 2007). Foi uma delas especialmente - a Oficina Católica Internacional de Cinema (OCIC) - que impulsionou ${ }^{3}$, no final dos anos 1960, o desenvolvimento do Plan DENI: Plan de Educación Cinematográfica de Niños, que influenciou a criação de projetos de educação audiovisual no Brasil, Argentina, Cuba, Chile, Uruguai, Paraguai, Peru, Equador e Bolívia (SANTOS, 2016).

Nos anos 1960 e 1970, a cinematografia latino-americana viveu um intenso intercâmbio cultural, estético e político, que marcou a consolidação de uma identidade cinematográfica na região. A Revolução Cubana e a criação do Instituto Cubano de Arte e Indústria Cinematográficos (ICAIC), menos de três meses após a derrubada do Governo de Batista, tiveram papel estratégico na fomentação e difusão do que veio a se chamar o "novo cinema latino-americano".

Com o triunfo da Revolução Cubana, o cinema foi nacionalmente reconhecido como um poderoso e sugestivo meio de expressão artística para a formação das consciências individual e coletiva. Ampliar o acesso do público ao cinema foi uma meta que a Direção do ICAIC assumiu por meio da realização do cinemóvel, que levou o cinema até os lugares mais longínquos da ilha. Sessões itinerantes de cinema foram às escolas, fazendas, sindicatos, fábricas, parques, associações de bairros, inclusive hospitais. De acordo com os dados levantados por Vilhaça (2010, p. 69), na década de 1970, havia mais de 100 "unidades móveis" que levavam, em jipes, mulas, barcos e até bicicletas, o cinema para muitas pessoas que nunca o haviam visto antes ${ }^{4}$.

\footnotetext{
${ }^{3}$ Para mais informações sobre a relação da OCIC com o Plan DENI, consultar a tese de Santos (2016).

4 O documentário "Por primera vez" (1968), de Octávio Cortázar, acompanha a experiência de cubanos que viram o cinema chegar pela primeira vez em sua região durante a vigência desse projeto.
} 
O ICAIC foi o órgão criado para ser responsável pela produção, distribuição e fomentação da sétima arte como instrumento popular capaz de construir uma visão de cinema político em Cuba e também em todo o continente. Nessas duas décadas, o Instituto foi palco de uma intensa troca cultural para artistas latino-americanos e europeus entusiasmados pela revolução estética que a ilha caribenha anunciava (VILHAÇA, 2010).

No final dos anos 1950, já se observavam, em vários países da América Latina, a recusa do cinema "comercial" e estrangeiro, a busca por temas regionais e autênticos, e o desenvolvimento de uma estética própria, capaz de conjugar arte, política e transformação social. A confluência de condições econômicas, sociais, culturais e políticas dos países latinoamericanos foi um cenário propício para uma identificação comum entre cineastas argentinos, brasileiros, bolivianos, cubanos, uruguaios e chilenos, que, isoladamente, buscaram mudar o cinema "de dentro" desde sua forma e conteúdo - nascia um novo cinema latino-americano (CASTILLO, 2012; VILHAÇA, 2010).

Foi nesse contexto que nasceu também o Plan DENI, em agosto de 1968, inicialmente em Quito, no Equador, e em Lima, no Peru, estendendo-se posteriormente para os países vizinhos. Essa, que é considerada a primeira iniciativa de cinema e educação integrada da América Latina, visava a atender às demandas da infância da época, que já se encontrava imersa na cultura audiovisual que se propagava. A proposta era reunir as crianças de diferentes classes sociais para assistirem aos filmes em salas públicas de cinema e estimular, em seguida, nas escolas, o diálogo e atividades sobre o que tinham visto. Esperava-se, com a experimentação do cinema, potencializar a educação das crianças na relação com a escola e com as famílias (GUSMÃO; KHOURI; SANTOS, 2015).

Os projetos influenciados pela metodologia do Plan DENI - fundamentada na relação entre percepção, crítica e expressão - construíram-se flexíveis às diferentes realidades socioeconômicas dos países onde foram implantados. Mas, mesmo assim, nem todos obtiveram êxito na continuidade da proposta.

Destaca-se no Brasil o CINEDUC ${ }^{5}$, que nasceu do Plan DENI em 1970 e é ativo até hoje, sendo a mais extensa ação de educação audiovisual da América Latina. Entidade sem fins lucrativos, o CINEDUC organiza atividades de aprendizagem e criação cinematográfica para escolas e outras instituições educativas. Realiza, também, a curadoria e promoção das principais mostras de filmes infantis no Rio de Janeiro, como a Mostra Geração ${ }^{6}$ do Festival Internacional de Cinema do Rio, além de mostras temáticas e comemorativas, difundindo o cinema como prática artística e cultural para um grande público de crianças e professores.

\footnotetext{
${ }^{5}$ Mais informações disponíveis em: www.cineduc.org.br.

${ }^{6}$ Mais informações em: http://mostrageracao.blogspot.com.br
}

(C) ETD-Educação Temática Digital Campinas, SP $\quad$ v.21 n.1 $\quad$ p.105-125 jan./mar. 2019 
Em Cuba, a apresentação da metodologia do Plan DENI aconteceu no primeiro encontro do Universo Audiovisual da Criança Latino-americana em 1988, organizado por Pablo Ramos dentro do Festival Internacional do Novo Cinema Latino-americano. Esses encontros reuniram, desde o final dos anos 1980, pesquisadores, educadores, realizadores e representantes de cineclubes da Argentina, Brasil, Colômbia, Cuba e México, dentre outros, em Havana, e contribuiu para fortalecer as trocas de experiências sobre a educação audiovisual na região (GUSMÃO et al., 2015). O resultado foi a consolidação da Rede $E I$ Universo Audiovisual de la Niñez Latinoamericana y Caribeña (UNIAL), em 1991, como um evento anual dentro do Festival, com o objetivo de integrar ações de pesquisa, produção, distribuição, capacitação e educação audiovisual na América Latina, acumulando, até o ano de 2015, 29 encontros.

Segundo Gusmão et al. (2015), a metodologia de trabalho da UNIAL parte de uma reflexão sobre o consumo audiovisual e a produção cinematográfica, pensando, a partir disso, processos de formação cultural. Herdeiros da metodologia do Plan DENI (percepção, intuição, crítica e expressão), as práticas na UNIAL visam a motivar o diálogo sobre os filmes solicitando, posteriormente, por exemplo, a criação de desenhos, escritas e produções outras sobre o que foi visto, investigando a relação das crianças com o filme e como o cinema poderia "ajudar" a escola, a família e a educação como um todo.

Tal como o movimento do "novo cinema latino-americano", que aconteceu sincronicamente em diferentes países da América Latina, perspectivas teóricas diversas acerca da educação para o audiovisual também surgiram e se multiplicaram pelo continente nesse período. Desde os anos 1970, quando tiveram início as primeiras iniciativas de educação cinematográfica para crianças e jovens, os pressupostos teórico-metodológicos dessas práticas foram se modificando. Inicialmente, a concepção do cinema como um produto cultural artístico orientava as atividades de cineclubes e cinedebates visando a um "chamado à consciência", à educação e à popularização das ideias.

A partir dos anos 1980, os intercâmbios acerca das necessidades e urgências na interseção infância, educação e mídias, além da influência dos estudos de mediação latinoamericanos, de Jesús Martín-Barbero, Néstor García Canclini e Santiago Castro Gómez, levaram à adoção de uma concepção ampliada de educação audiovisual, que se consolidou na ideia da educação para a comunicação e posteriormente de "educomunicação".

Os projetos que partiram do Plan DENI já falavam de orientar para a aprendizagem da linguagem fílmica superando os "cinedebates" que focavam na discussão sobre conteúdos. E se, no início, apenas o cinema era tomado como objeto de análise, com o processo de expansão das mídias, uma concepção ampliada de educação para a comunicação foi ganhando espaço nas discussões da UNIAL: "Uma derivação disso foi o movimento de entender a educação cinematográfica em um contexto mais amplo de educação para a comunicação" (RAMOS, 2005, p. 117).

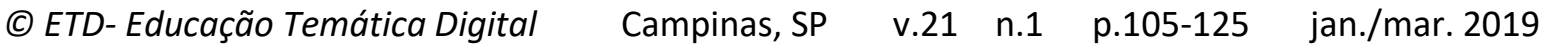


De fato, observamos um número expressivo de iniciativas de educação audiovisual em Cuba e no Brasil, as quais são atravessadas pela ideia do que veio a se chamar "educomunicação". Nos anos 1960, também, estava em pauta o desenvolvimento acelerado das novas tecnologias da informação e comunicação (TIC) e sua integração à escola e contribuição no processo social educativo como um todo. A incorporação das TIC carecia de reflexões sobre mensagens e contextos de produção, bem como de conhecimentos sobre essa nova linguagem (visual), em contraste com um cenário onde o conteúdo da produção midiática era cada vez mais preocupante e se consolidava a exploração de imagens de violência.

Apontava-se, portanto, que as crianças e também os adultos - pais, professores e educadores - não recebiam uma educação específica para a relação com os "meios", que, por sua vez, exibiam cada vez mais sua força na produção de gostos, posturas, comportamentos, desejos e visões de mundo (SOARES, 2002, 2014; FANTíN, 2014). Nesse contexto, foi ganhando espaço e visibilidade na América Latina uma outra leitura para a relação da educação com o audiovisual: a Mídia-Educação.

Em resposta a esse cenário, foi se consolidando a necessidade de uma educação "com" os meios (uso didático dos filmes em contextos educativos), "sobre" os meios (aprendizagem de leitura crítica das imagens e análise fílmica) e "através" dos meios (produção audiovisual). Hoje, fala-se de novos letramentos que envolvem a leitura do mundo a partir de uma comunhão da produção escrita, artística, audiovisual, midiática e digital - multiliteracies (FANTíN, 2014).

Assim, para se relacionar e se comunicar no mundo contemporâneo, os pesquisadores dessa vertente consideram necessária uma alfabetização específica para a apropriação crítica e criativa das imagens. Conceitos e expressões como linguagem total, digital e media literacy, alfabetização audiovisual, educação para a comunicação, educação para as mídias, educação audiovisual e mediação, dentre outras possibilidades de se pensar a educação em meio às novas formas de se comunicar e educar, têm inspirado encontros, trabalhos e intercâmbios de práticas e pesquisas na América Latina.

Para Soares (2009, 2014), a Mídia-Educação alargou sua intervenção e capacidade de transformação social com o nascimento do paradigma da "educomunicação", que significou a incorporação da variedade dos meios de comunicação, e não um foco na aprendizagem audiovisual. Ele acrescenta ainda o entendimento de que a educação é um modo e uma prática específica de comunicação e se fundamenta no diálogo - o que o levou a descrever a educação para a comunicação como a própria "educação popular".

No contexto das práticas de educação cinematográfica na América Latina, especialmente em Cuba, Ramos (2005) reconhece certa "evolução" no movimento de abarcar todas as mídias, e não "apenas" o cinema, significando, em sua opinião, maior abrangência de atuação para a educação audiovisual. Entendo, entretanto, amparada na 
pesquisa de campo que realizei em Havana e no acompanhamento dos Fóruns da Rede KINO no Brasil, que se trata apenas de um modo, dentre outros, de se pensar a relação da educação com as imagens em movimento.

De fato, em Havana, por intermédio da Rede UNIAL, acompanhei práticas de audiovisual e educação que corroboraram essa proposta/opinião dos autores: elas se apoiavam no referencial teórico da "educomunicação" e algumas até em conjunto com a prática da educação popular. Nas entrevistas com as equipes de projetos variados, os educadores locais diziam trabalhar com "educomunicação" e/ou integrar a Rede de Educadoras e Educadores Populares do Centro Memorial Martín Luther King $(\mathrm{CMLK})^{7}$, tais como representantes do Proyecto Escaramujo e do $A+-$ Espacios Adolescentes $^{9}$. Até mesmo as palhaças da Companhia de Teatro Infantil La Colmenita, que realizam atividades de fotografia e stop motion com crianças hospitalizadas, frequentavam cursos de educação popular junto ao CMLK.

Um movimento metodológico parecido é apresentado pela pesquisa de Toledo (2009), na qual descreve experiências de Educação Audiovisual Popular (EAP) ${ }^{10}$ em todo o Brasil, entre 1990 e 2009, no formato de oficinas livres ${ }^{11}$. Na perspectiva da autora, a EAP é a comunhão de práticas, metodologias e relações pedagógicas para o ensino audiovisual, as quais se apoiam no pensamento de Paulo Freire (mas não limitadas a ele) e são compartilhadas por quase uma centena de experiências de ensino do audiovisual fora da escola em mais de 40 cidades por todas as regiões do Brasil.

Depois de trabalhar por dez anos em diferentes projetos de educação audiovisual para comunidades desfavorecidas, Toledo (2009) retornou ao campo como pesquisadora, a fim de buscar traços de sistematização e amadurecimento da área e entender como o trabalho era feito no País. Nesse processo, ela se propôs a identificar uma base conceitual, historicamente omitida, porém consistente, que sustentava essas práticas de educação audiovisual.

Paulo Freire foi citado em mais de $80 \%$ dos projetos que pesquisou, e a autora identificou práticas e preceitos freirianos até mesmo nos discursos de entidades que não o citavam diretamente. Além disso, havia referências às propostas pedagógicas alternativas, como as escolas democráticas Summerhill, na Inglaterra, e a Escola da Ponte, em Portugal, como também aos clássicos como Freinet e Vigotski.

\footnotetext{
${ }^{7}$ Mais informações em http://cmlk.org/article/red-de-educadoras-y-educadores-populares/

${ }^{8}$ Mais informações em https://letrajoven.wordpress.com/2013/07/29/escaramujo-proyectoeducomunicativo-de-la-facultad-de-comunicacion/

${ }_{9}^{9}$ Mais informações em https://www.facebook.com/proyectoespaciosadolescentes/

${ }^{10}$ Termo criado pela autora.

${ }^{11}$ Informações sobre as 113 instituições pesquisadas por Toledo estão disponíveis no site http://kinooikos.com.
} 
O ensino audiovisual com a perspectiva de uma educação popular fora da escola tem como antecedente o movimento Vídeo Popular, como o videomilitante, o videocomunitário contemporâneo ou o vídeo de localidade entre outros termos que tentaram definir a emergência de novas práticas sociais com o audiovisual desde o final dos anos 1970 e fortalecida nos anos 1990 com a popularização das câmeras digitais (ALVARENGA, 2004). De modo geral, a expressão Vídeo Popular designa uma variedade de projetos, grande parte atrelados a movimentos sociais para produção de vídeos como expressão política de sindicatos, ativistas de bairro, grupos estudantis e movimentos culturais. "[...] em plena ditadura militar, o Vídeo Popular emerge como forma de diversificar as estratégias de comunicação das então crescentes organizações sociais", explica Toledo (2009, p. 50).

Conforme a autora, houve um caminho histórico que conduziu o Vídeo Popular à Educação Audiovisual Popular (EAP), especialmente em se tratando do público-alvo e das ações nas comunidades. Todavia, no que diz respeito às estratégias pedagógicas do movimento, a autora afirma que estas não eram sistematizadas, e um dos desafios do Vídeo Popular foi aliar a formação técnica à participação efetiva dos sujeitos. Havia o "desejo de que as câmeras estivessem nas mãos das pessoas para que elas próprias pudessem tomar imagens do mundo", destaca Toledo (2009, p. 51).

Esse processo foi acontecendo à medida que diferentes experiências, as quais integravam o movimento do Vídeo Popular, se uniram na direção de uma formação técnica aliada à participação (ALVARENGA, 2004). A carência de referências metodológicas, bibliográficas e formativas para o educador audiovisual acabou por revelar um campo pedagogicamente fértil na busca de práticas alternativas ao modelo escolar. Esse processo permitiu uma atualização dos objetivos e estratégias pedagógicas dos projetos, culminando em práticas e pensamentos que foram conformando a ideia da Educação Audiovisual Popular (EAP).

Poucas organizações do Vídeo Popular se mantiveram ativas nesse processo de mudança e reestruturação pedagógica e "filosófica" que aconteceu nos anos 1990. O formato que foi surgindo com mais visibilidade foi a oferta de oficinas audiovisuais pelas ONGs, OSCIPs e afins. Observamos, hoje, um panorama de ofertas de cursos de audiovisual bastante múltiplo: oficinas livres (em sua maioria não profissionalizantes) e cursos de extensão, graduação e pós-graduação lato sensu em universidades, que não podem ser enquadrados como respondendo apenas a uma ou a outra metodologia.

Se nos anos 1990, especialmente no Brasil, foi a popularização da câmera digital que propiciou o fortalecimento do campo, hoje podemos acrescentar novos fatores que vêm contribuindo para uma variedade de apropriações na relação com o cinema. Em primeiro lugar, identificamos uma reflexão acerca dos limites do modelo moderno de educação. As tecnologias digitais, a familiaridade com que crianças e jovens se expressam pelo universo das imagens e as identidades exteriorizadas vêm construindo novas subjetividades 
contemporâneas e têm gerado polêmicas na tradição escolar da escrita. Muitas vezes, o cinema é chamado como alternativa para responder a essas questões (SIBILIA, 2012).

Outro aspecto relevante é que, nos últimos 15 anos, tivemos a retomada da produção cinematográfica brasileira com novas políticas culturais, o aumento do número de editais para financiamento de obras audiovisuais e a multiplicação e consolidação de Festivais e Mostras de Cinema em todo o País. Juntamente com isso, surgiu um novo movimento cineclubista e foram abertos cursos de audiovisual tanto universitários quanto novos projetos no modelo de oficinas dentro e fora das escolas (NORTON, 2013) ${ }^{12}$.

Por último, e talvez o fator mais direto, destacamos a aprovação da Lei no 13.006 (BRASIL, 2014), que regulamenta a obrigatoriedade de filmes nacionais na Educação Básica. Identificando um apartheid cultural de grande parte das crianças que desconhecem a produção do cinema brasileiro, em desequilíbrio à exposição massiva a filmografias estrangeiras, o senador Cristovam Buarque aprovou, em 2014, seu projeto de lei (PLS no 185/2008) modificando o artigo 26 da Lei 9.395/1996 e acrescentando ao parágrafo $8^{\circ}$ a seguinte redação: "A exibição de filmes de produção nacional constituirá componente curricular complementar integrado à proposta pedagógica da escola, sendo a sua exibição obrigatória por, no mínimo, 2 (duas) horas mensais" (BRASIL, 2014).

Essa conjunção de fatores vem incitando a reinvenção da relação do cinema com a educação a partir de múltiplos pontos de vistas, que incorporam as dimensões artística, midiática, cultural e expressiva da obra cinematográfica. Sendo assim, mesmo em Cuba, onde a presença da educação popular é significativa como um polo de encontro e formação de toda a América Latina, não podemos dizer que todos os projetos estão referendados na "educomunicação", já que algumas iniciativas, como o projeto Cintio Vitier e o projeto Muraleando ${ }^{13}$, congregavam às oficinas de audiovisual o ensino de desenho, escultura e criação com uma variedade de materiais expressivos que demandavam uma hibridização de abordagens artísticas e pedagógicas.

Ao analisar as variedades de práticas de ensino audiovisual e conectá-las com algumas teorias do cinema que o concebem como "substituto do olhar, arte, linguagem, escrita, pensamento ou manifestação de afeto e simbolização do desejo" (AUMONT; MARIE, 2012, p. 289-291), Fresquet (2013) destaca que a perspectiva do cinema como arte é a mais ausente desse cenário, e isso se reflete nas produções. O aumento quantitativo das produções audiovisuais de crianças e adolescentes não significa, necessariamente, uma

\footnotetext{
12 Como já destacamos, a pesquisa de Toledo (2009) fornece um panorama expressivo dessas práticas no período de 1990 a 2009. A dissertação de Norton (2013) aponta iniciativas mais recentes, destacando cursos universitários e oficinas de cinema dentro das escolas, que não foram contemplados no trabalho de Toledo, que lhe é anterior.

${ }^{13}$ Mais informações em: http://www.muraleando.org
}

(C) ETD-Educação Temática Digital Campinas, SP $\quad$ v.21 $\quad$ n.1 $\quad$ p.105-125 jan./mar. 2019 
pluralidade na expansão de olhares, já que a maioria evoca formatos parecidos com as novelas e comerciais do momento.

Como suplantar a imitação, inventando ou reinventando, a partir do que nos chega, imagens, afetos e línguas outras, atualizando a latente originalidade latino-americana de que nos falavam Martí e Rodríguez?

A criação no Brasil, em 2009, da Rede KINO (Rede Latino Americana de Educação, Cinema e Audiovisual) ${ }^{14}$, incorporou essas recentes problematizações acerca da relação cotidiana com o ver e produzir imagens. Reconhecendo o número crescente de ações em cinema-educação na América Latina, a necessidade de intercâmbio sobre as diferentes práticas e metodologias, a dificuldade de articulação entre educadores, pesquisadores, cineastas e produtores para superar a distância entre produção artística e formação humana, as professoras Inês Assunção de Castro Teixeira (UFMG), Milene de Cássia Silveira Gusmão (UESB), Rosália Duarte (PPGE/PUC-Rio) e Adriana Fresquet (PPGE/UFRJ), como também as professoras Bete Bullara e Marialva Monteiro (CINEDUC-RJ), convocaram os demais grupos de pesquisas e cineclubistas a consolidarem essa rede "herdeira" das reflexões políticas que procuramos esboçar nas linhas anteriores.

Conhecendo as Cartas Públicas ${ }^{15}$ elaboradas nos fóruns da KINO, que desde 2010 acontecem na Mostra de Cinema de Ouro Preto/MG (CineOP) ${ }^{16}$, é possível identificar ininterruptas preocupações históricas, as quais, dentre outras, envolvem articular projetos em cinema-educação no território com vistas a uma educação estética que nos aproxime, nos seja comum, destruindo uma (e reerguendo outra que nos seja própria?) trincheira de ideias de que falava Martí. A cada ano, os integrantes da KINO reafirmam o compromisso com uma educação estética cinematográfica, manifestam o apoio ao então projeto de lei $n^{\circ}$ 185/2008 e, em meio a ela, pensam a formação do público cinematográfico não ditado pelos valores da indústria, mas por uma pluralidade de imagens sobre o Brasil e a América Latina representativa da diversidade de nosso patrimônio cultural.

A Carta Pública de 2011 aponta a necessidade de um mapeamento dos programas e projetos e defendem, no caso de obras financiadas pelo poder público, a flexibilização dos direitos autorais de exibição nas escolas e organização comunitárias, o que exige, por sua vez, uma articulação entre os Ministérios da Educação e da Cultura no âmbito de políticas públicas. O texto da Carta de 2012 faz menção à defesa de uma formação estético-cultural contra-hegemônica e descolonizadora, o que pode ser principiado. Sugere-se, com a integração dos cinemas nacional e latino-americano, uma possível plataforma online de

\footnotetext{
${ }^{14}$ http://www.redekino.com.br

${ }^{15}$ As cartas completas estão disponíveis em: http://www.redekino.com.br/memoria/

${ }^{16}$ http://cineop.com.br/programacao/seminario
} 
compartilhamento audiovisual, que a Programadora Brasil ${ }^{17}$ poderia servir de referência, proposta inviabilizada com seu trágico fim no ano seguinte.

Na Carta de 2013, acrescenta-se ao discurso a necessidade de ampliar as práticas de cinema-educação para crianças e jovens em situação de risco além da escola e o fomento de espaços alternativos para exibição dos filmes produzidos nesses e outros territórios. Pensase, ainda, nas estratégias e na importância de se fazer presente, na formação inicial e continuada de professores, as reflexões conceituais, políticas e metodológicas sobre cinema-educação, que vêm se construindo nos fóruns, especialmente atravessados pela expectativa da aprovação da Lei no 13.006 (BRASIL, 2014).

Assim, nos anos seguintes, as proposições giraram em torno de como regulamentar seu funcionamento e garantir condições minimamente adequadas para uma exibição frente a precariedade das estruturas físicas das escolas públicas brasileiras. Reiterou-se, então, no contexto da Lei, a urgência de se pensar numa curadoria cinematográfica capaz de resistir ao mercado audiovisual, que pouco reflete nossa diversidade ética, geográfica, social e cultural. Trata-se de ampliar as possibilidades de escolhas em meio à educação de um gosto que tenha passado por algum tipo de reflexão estética crítica e criativa.

A aproximação do cinema com outras artes da imagem começa a se fazer mais explícita nos documentos e encontros recentes da KINO, resultando em uma concepção de cinema expandido e em uma relação com obras audiovisuais como experiência estética e encontro com a alteridade. Uma mestiçagem que podemos identificar é o diálogo com a "pedagogia da criação" do francês Alain Bergala (2008), cuja experiência na coordenação de um programa que levou o cinema como arte para as escolas franceses tem inspirado projetos e produção de materiais pedagógicos.

Nesse cenário, o que a KINO identifica, quase dez anos após a pesquisa realizada por Toledo (2009), é o reconhecimento da emergência de outras metodologias e referências teóricas para o ensino e aprendizagem de cinema, que vêm influenciando práticas latinoamericanas. Assim, aparece, pela primeira vez, de modo mais propositivo, na Carta de 2015, a necessidade de uma sistematização das metodologias empregadas nos diversos projetos

\footnotetext{
17 Desativada desde 2013, tratava-se de um dispositivo de acesso ao cinema brasileiro da Secretaria do Audiovisual (SAv) do Ministério da Cultura, que visava a formar plateias e incentivar o pensamento crítico em torno da produção nacional. Sua programação constituía um acervo representativo da cinematografia brasileira, composto desde os primeiros filmes nacionais de ficção do início do século XX até as mais recentes produções brasileiras em todos os gêneros. Suas diretrizes contemplavam a política de inclusão de recursos de acessibilidade em filmes e vídeos. Sua presença vinha sendo ainda mais relevante no interior do País, junto a projetos, pontos de cultura e iniciativas comunitárias e universitárias, onde, em alguns municípios, era a única alternativa cinematográfica existente. Todas essas características fazem da proposta um dispositivo pedagógico para a educação cinematográfica em âmbitos nacional e intergeracional, de fomento, valorização e distribuição da produção artística e cultural brasileira em consonância direta com as diretrizes da Lei no 13.006 (BRASIL, 2014).
} 
que vêm acontecendo nos fóruns - mais um dentre tantos desafios que a Lei começa a colocar ao campo.

É preciso consolidar o cinema e a educação como um campo de conhecimento, proposições e história própria, a fim de subsidiar e influenciar políticas. Gusmão et al. (2015), ao analisarem as primeiras iniciativas em cinema-educação e as condições para tanto, apontam que somos herdeiros desta história, respondendo a acúmulos e trocas de fluxos dinâmicos com rupturas e continuidades.

Aos modos de Simón Rodríguez, pesquisadores brasileiros vão "com" e "contra" Bergala, por exemplo, ao tomar a experiência do cineasta francês como ponto de partida para reinventar novos dispositivos (MIGLIORIN et al., 2016) e ao defender um "lugar oficial" para o cinema dentro da escola. O cinema brasileiro, com imagens outras capazes de mobilizar o pensamento para intervenções e rachaduras nos saberes hegemônicos, precisa, sim, estar no cotidiano escolar dada a falta de políticas culturais que assegurem a presença da sétima arte na formação e o racismo epistêmico que domina o campo do currículo.

Ao contrário da posição de Bergala (2008) de que o cinema fique como um estrangeiro fora da grade escolar, para que não se funcionalize a arte e nem se reduza o cinema à submissão dos conteúdos escolares, no Brasil e na América Latina, a falta de protecionismo com o cinema interno ajudou a naturalizar imagens coloniais de dominação, reforçou um pernicioso desconhecimento das realidades vizinhas e engendrou a criação de um imaginário que supervaloriza os saberes do Norte em detrimento da cultura sulista. Conhecemos - e desejamos - mais os modos e costumes europeus e estadunidenses do que as dores e desafios dos países com quem dividimos fronteiras.

Esta é, para Rodríguez (2016), a verdadeira ignorância: o desconhecimento do sofrimento do outro. É ignorante todo aquele que não sente a dor alheia como própria, que não pode sentir o outro no próprio corpo e que é indiferente à alteridade. Trata-se de uma postura psicossocial de empatia, que pode e precisa ser aprendida e cultivada como condição de nossa humanidade, já que é inumano privar o homem dos conhecimentos de que necessita para se entender com seus semelhantes, alertava Rodríguez. Vivemos, portanto, uma inumanidade latino-americana reforçada por imagens colonialistas trincheiras para nosso contato.

E como promover o encontro? Como conhecer uns aos outros?

O cinema surgiu muito depois de Rodríguez (2017, p. 142), mas suspeitamos que teria visto na sua forte impressão de realidade uma potência da experiência da alteridade que tanto desejava aos povos da América: "Povos que não se conhecem devem ter pressa em se conhecer", dizia ele. E o cinema aproxima o outro no tempo e no espaço. Com ele, tomamos "olhos emprestados" para conhecer paisagens. Ele torna comum o que não nos pertence e permite conhecermos culturas, costumes de outros países e épocas, assim como

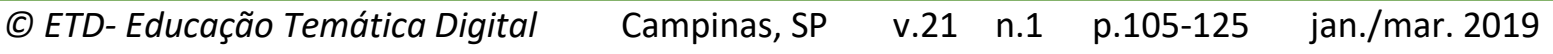


conhecermos melhor e mais profundamente nós mesmos (DUARTE, 2009; FRESQUET, 2009, 2013).

É nesse espírito que a Mostra de Cinema de Ouro Preto de 2017 colocou em evidência as "Emergências Ameríndias", aproximando-nos de cineastas (indígenas e não indígenas), que produzem imagens autóctones de modos de vidas outros, os quais nos ajudam (re)conhecer e a (re)descobrir o Brasil e tantas vidas que aqui habitam:

[...] nos posicionarmos ao lado dessas populações que vêm sendo exterminadas pelo Estado brasileiro, o neoliberalismo, o agronegócio e, a um só tempo, nos conectar com sua produção subjetiva, com seus modos de ver, ouvir e falar sobre o mundo. Com suas maneiras de aprender e ensinar. Assim, gostaríamos de nos aproximar de toda a cosmologia que cerca a produção recente de diversas etnias indígenas, buscando perceber como essa forma de convívio entre nossos pensamentos ocidentais e ameríndios podem nos recolocar em relação a um mundo atravessado por diversos sintomas. Uma necessária visada à nossa história, uma história ainda desconhecida (FRESQUET; PIPANO, 2017).

Segundo Cardoso e Fresquet (2017), o filme "Martírio" (2016), de Vincent Carelli, Ernesto Carvalho e Tita, produzido pelo Projeto Vídeo nas Aldeias ${ }^{18}$ e exibido nessa última edição, é emblemático do cinema que queremos dentro e fora da escola. "Martírio" denuncia um projeto de nação, que prega a dissolução dos índios e o desaparecimento da diversidade, abrindo brechas de colonialistas em meio aos estereótipos e preconceitos sobre quem são, como vivem, o que pensam e como resistem os povos originários de nossa América. Nesse sentido, é o "cinema imperfeito" de que falava García Espinosa (1970): feito de modo visceral, singular em seus processos e profundamente revolucionário na versão a contrapelo da história que coloca em evidência.

\begin{abstract}
Martírio é um documentário que expressa a profunda indignação de Carelli e que contamina seus/suas espectadores/as. Martírio é um filme-ruína. Vincent nos coloca frente a frente com nós mesmos como ruínas. Ruínas que precisam ser ocupadas com ações, proposições, com movimentos e eventos que colaborem com a luta dos diferentes povos indígenas frente a hegemonia do agronegócio. Ao mesmo tempo, revela a poesia com que os/as Kaiowá e Guarani lutam para existir (CARDOSO JUNIOR; FRESQUET, 2017, p. 14).
\end{abstract}

Assim, a KINO ${ }^{19}$, com o apoio da Mostra de Cinema de Ouro Preto (CineOP), vem contribuindo para um duo de encontros: por um lado, os Fóruns anuais (que também já vêm acontecendo em caráter regional ${ }^{20}$ ) são uma oportunidade para diferentes iniciativas em cinema-educação, de tempos e metodologias diversas, partilharem, aprenderem, crescerem e se fortalecerem - esse é um primeiro encontro. Por outro, consolidando-se como espaço político de proposição, produção e pesquisa em cinema-educação, os Fóruns têm nos

\footnotetext{
${ }^{18}$ http://www.videonasaldeias.org.br

${ }_{19}$ Nos catálogos da Mostra de Cinema de Ouro Preto, é possível verificar a programação de temáticas e convidados a cada edição da KINO, ou ainda no site http://cineop.com.br/a-mostra/edicoes-anteriores. Para os encontros da Rede UNIAL, ver https://pt-br.facebook.com/pg/Red-UNIAL-117408648358297/about/

${ }^{20}$ Como a I Mostra KINO Campinas. Disponível em https://www.fe.unicamp.br/eventos/mostrakino/ e o I Encontro KINO Minas na Universidade Federal de São João del-Rei (UFSJ) em 2018.
}

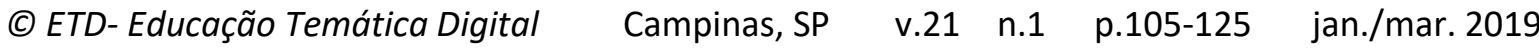


aproximado de imagens que foram excluídas do enquadre hegemônico. Mobilizados pela Lei no 13.006 (BRASIL, 2014), viemos aprendendo a desaprender a história que nos foi mostrada e a resgatar a dívida epistêmica com cineastas, cinemas e narrativas silenciadas.

\section{CINEMA-(RE)EDUCAÇÃO DA AMÉRICA LATINA}

Os encontros de educadores, pesquisadores, alunos e professores envolvidos com cinema-educação, especialmente no âmbito da KINO, vêm acompanhando os processos político-sociais no Brasil e dialogando com esses desafios a partir de suas imagens. Dessa forma, as ocupações secundaristas, por exemplo, e os diferentes modos de construir sentidos sobre esse movimento de resistência estiveram presentes no Fórum de 2016. A exibição do filme "Acabou a paz. Isso aqui vai virar o Chile"21, de Carlos Pronzato - que, por seus modos de produção, temática e circulação, também é um "cinema imperfeito" -, aqueceu a discussão que se assentou sobre uma temática ainda maior: refletir sobre a trajetória política brasileira desde a ditadura tendo o Golpe de 2016 preso na garganta.

Assim, as Cartas Públicas da KINO dos últimos dois anos refletem sobre o "aborto" de nossa democracia embrionária, violentada pelos desejos do capital, que tenta desatar elos de uma rede que vinha sendo gradativamente (re)trançada. Perguntamo-nos sobre que outros agentes mobilizar e sobre o que é possível continuar fazendo. Como pensar os filmes produzidos nos projetos audiovisuais que habitam nossa América num contexto de (re)insurgência conservadora em um momento em que uma nova revolução ainda carece "por vir"?

Vimos que fazer cinema em tempos pós-revolução era uma condição de sobrevivência, de afirmação da revolução. Esse cinema é imperfeito não apenas porque seus modos de produção e distribuição se afastam dos modelos tradicionais e aparelhagens ideais, mas especialmente porque ainda não é feito pelo povo, e o verdadeiro cinema, a "verdadeira arte", com o fim das classes, seria aquela em que todos criam para todos (GARCÍA ESPINOSA, 1970).

Nessa perspectiva, talvez, possamos dizer que as imagens produzidas nos diversos contextos pela América Latina, em projetos educativos ou exercícios livres em salas de aula, enfermarias, com câmeras de celulares, tablets, dispositivos tecnológicos alternativos às câmeras de alta definição, microfones e programas de edição, se aproximam do "cinema imperfeito" e necessário de García Espinosa. Temáticas menos privilegiadas institucionalmente, ou até "proibidas", ganham visibilidade com a criação cinematográfica nestas ações: o recreio, as brincadeiras, as histórias imaginadas e/ou inventadas, as conversas com atores institucionais ou da comunidade pouco conhecidos e os espaços físicos da escola/do hospital/da vizinhança pouco visitados.

${ }^{21}$ Disponível em: https://www.youtube.com/watch?v=LK9Ri2prfNw

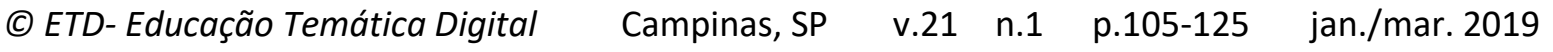


Outra caraterística "revolucionária" que podemos identificar nesse exercício de fazer cinema é o seu modo de exibição e circulação, via Mostras Escolares, Festivais locais, trocas de filmes entre escolas e outras instituições, isto é, a criação de espaços à margem, que fomentam formas alternativas de "distribuição" e intercâmbio sobre a experiência do fazer, as dificuldades do processo e as aprendizagens.

Consideramos esses filmes e tantos outros produzidos na América Latina ainda imperfeitos, e exatamente por isso - revolucionários - feitos com paixão, motivados pelo desejo de aprender para criar sentidos e imagens outras sobre nossa América. Quando crianças, jovens, adultos, idosos, professores, educadores, indígenas, quilombolas, camponeses e caiçaras produzem suas imagens, pensamos que a criação e a partilha de metodologias para ensinar e aprender cinema contribuem, mesmo que timidamente, para a "perfeição" de um cinema produzido pelo povo, o qual sonhava García Espinosa. Como num devaneio de desejo e esperança martiniano, filmes produzidos por iniciantes, aprendizes e cineastas "marginais" permitem que os povos se levantem, se cumprimentem e se perguntem "quem somos?", e uns a outros vão dizendo como são.

Quantos, tantos, quais filmes brasileiros e latino-americanos também precisam ser vistos e inventados para realizarmos esses sonhos de outrora ainda tão urgentes?

Esperamos que este início de conversa possa contribuir para práticas e metodologias latino-americanas em cinema e educação. Pensamos que talvez o cinema e os processos em torno de como vivê-lo no encontro com o outro, especialmente no contexto dos projetos educativos e sujeitos aqui comentados, assentam concretude para sonhos e esperanças que desde sempre habitam nosso território e imaginário.

\section{REFERÊNCIAS}

ALVARENGA, Clarisse. Vídeo e experimentação social: um estudo sobre vídeo comunitário no Brasil. 2004. Dissertação (Mestrado em Multimeios) - Universidade Estadual de Campinas, Campinas, 2004.

AUMONT, Jacques; MARIE, Michel. Dicionário teórico crítico de cinema. 5. ed. Campinas, SP: Papirus, 2012.

BERGALA, Alain. A hipótese-cinema: pequeno tratado de transmissão do cinema dentro e fora da escola. Rio de Janeiro: Booklink; CINEAD-LISE-FE/UFRJ, 2008.

BRASIL. Lei $n^{\circ}$ 13.006, de 26 de junho de 2014. Acrescenta $\S 8^{\circ}$ ao art. 26 da Lei $n^{\circ} 9.394$, de 20 de dezembro de 1996, que estabelece as diretrizes e bases da educação nacional, para obrigar a exibição de filmes de produção nacional nas escolas de educação básica. Brasília, DF, 2014. Disponível em: http://www.planalto.gov.br/ccivil 03/ Ato20112014/2014/Lei/L13006.htm. Acesso em: 27 maio 2018.

CARDOSO JUNIOR, Wilson; FRESQUET, Adriana. Cinema, educação e interculturalidade: Martírio, o filme. Revista Digital do LAV, Santa Maria, v. 10, n. 2, p. 120-139, maio/ago. 2017.
(C) ETD- Educação Temática Digital
Campinas, SP
v.21
n.1
p.105-125
jan./mar. 2019 
CASTILLO, Luciano. Los airados años 60. En: TORCHIA, Édgar Soberón. Los cines de América Latina y el Caribe. La Habana: Ediciones EICTV, 2012.

CASTRO-GOMEZ, Santiago. La poscolonialidad explicada a los niños. Bogotá: Universidad Del Cauca; Instituto Pensar, 2005.

CATELLI, Rosana. Dos "naturais" ao documentário: o cinema educativo e a educação do cinema entre os anos de 1920 e 1930. 2007. Tese (Doutorado em Artes) - Universidade Estadual de Campinas, Campinas, 2007.

CORTÁZAR, Octávio. Por primera vez. 1968. Disponível em: https://www.youtube.com/watch?v=Z8qo4drijuo . Acesso em: 27 maio 2018.

DUARTE, Rosália. Cinema e educação. Belo Horizonte: Autêntica, 2009.

FANTÍN, Mônica. Audiovisual na escola: abordagens e possibilidades. In: BARBOSA, Maria Carmen; SANTOS, Maria Angélica (Org.). Escritos de alfabetização audiovisual. Porto Alegre: Libretos, 2014.

FRESQUET, Adriana (Org.). Aprender com experiências do cinema. Rio de Janeiro: Booklink; CINEAD-LISE-FE/UFRJ, 2009.

FRESQUET, Adriana. Cinema e educação: reflexões e experiências com estudantes de educação básica, dentro e "fora" da escola. Rio de Janeiro: Autêntica, 2013.

FRESQUET, Adriana; PIPANO, Isaac. Educação: emergências ameríndias, 2017. Disponível em: http://cineop.com.br/a-mostra/educacao Acesso em: 27 maio 2018.

GARCÍA ESPINOSA, Julio. Por un cine imperfecto. Caracas: Fondo Editorial Salvador de la Plaza, 1970.

GUSMÃO, Milene; KHOURI, Macelle; SANTOS, Raquel. Processos de formação pelo cinema, entre trajetórias, planos e redes: em que medida o passado nos impacta ou inspira? In: FRESQUET, Adriana (Org.). Cinema e educação: a Lei 13.006 - reflexões, perspectivas e propostas. Belo Horizonte: Universo Produção, 2015. p. 51- 66.

KOHAN, Walter Omar. 0 mestre inventor. Relatos de um viajante educador. Belo Horizonte: Autêntica, 2013.

LISBOA, Fátima Sebastiana Gomes. O cineclubismo na América Latina: ideias sobre o projeto civilizador do movimento francês no Brasil na Argentina (1940-1970). In: CAPELATO, Maria Helena et al. História e cinema: dimensões históricas do audiovisual. São Paulo: Alameda Casa Editorial, 2007.

MACHADO, Arlindo. Pré-cinemas \& pós-cinemas. Campinas, SP: Papirus, 1997.

MARTí, José. Nuestra América. Revista Ilustrada de Nova York, 1891. Disponível em: http://bibliotecavirtual.clacso.org.ar/ar/libros/osal/osal27/14Marti.pdf . Acesso em: 27 maio 2018.

MIGLIORIN, Cézar et al. Cadernos do Inventar: cinema, educação, direitos humanos. Niterói, RJ: EDG, 2016. Disponível em: http://www.inventarcomadiferenca.org/wp-

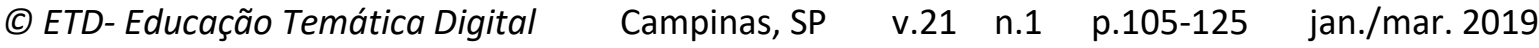


content/uploads/2017/05/Cadernos do Inventar com Diferenca.pdf. Acesso em: 27 maio 2018.

NORTON, Maíra. Cinema Oficina: técnica e criatividade no ensino do audiovisual. Niterói: Ed. da UFF, 2013.

NUÑEZ, Fabián. Afinal, o que é "cine imperfecto?" Uma análise das ideias de García Espinosa. Revista Brasileira de Estudos de Cinema e Audiovisual, Ano 1, n. 1, p. 172-194, 2012.

RAMOS, Pablo. De la educación cinematográfica a la educación para la comunicación en Cuba. Revista Cientifica de Comunicación y Educación, n.24. p. 113-119, 2005.

RODRÍGUEZ, Simón. Inventamos ou erramos. Belo Horizonte: Autêntica, 2016.

SALIBA, Maria. Cinema contra cinema: o cinema educativo de Canuto Mendes (1922-1931). São Paulo: Annablume, FAPESP, 2003.

SANTOS, Raquel Costa. Um trajeto católico de educação pelo/para o cinema no Brasil: redes, práticas e memórias. 2016. Tese (Doutorado em Memória: Linguagem e Sociedade) Universidade Estadual do Sudoeste da Bahia, Vitória da Conquista, 2016.

SIBILIA, Paula. Redes ou paredes. A escola em tempos de dispersão. Rio de Janeiro: Contraponto, 2012.

SOARES, Ismar de Oliveira. Gestão Comunicativa e Educação: caminhos da Educomunicação. Comunicação e Educação, São Paulo, n. 23, p. 16-25, jan./abr. 2002.

SOARES, Ismar de Oliveira. Caminos de la Educomunicación: utopias, confrontaciones, reconocimientos. Nómadas, Universidad Central, Colombia, n. 30, p. 194 - p. 207, abr. 2009.

SOARES, Ismar de Oliveira. Educação Midiática: vertentes históricas de aproximação entre Comunicação e Educação. Revista Educomunicação e Educação Midiática, Ano 19, n. 2, p. 15-26, jul./dez. 2014.

TOLEDO, Moura. Educação audiovisual popular no Brasil: panorama 1990-2009. 2009. Tese (Doutorado em Comunicação e Artes) - Universidade de São Paulo, São Paulo, 2009.

TORCHIA, Édgar Soberón. Los cines de América Latina y el Caribe. La Habana: EICTV, 2012. v. I-II.

VILHAÇA, Mariana. Cinema Cubano: Revolução e Política Cultural. São Paulo: Alameda, 2010.

Revisão gramatica do texto sob responsabilidade de: Rogerio Lucas de Carvalho E-mail: gerocarvalho@hotmail.com 